\title{
The Interplay of Biology and the Environment Broadly Defined
}

\author{
Adele Diamond \\ University of British Columbia and BC Children's Hospital
}

\begin{abstract}
This special section of Developmental Psychology contains articles on the interplay of biology and the environment, broadly defined, that have the potential to change or challenge how developmental psychologists think. Topics include how experience affects gene expression; how genes affect how the environment is experienced and what effect the environment has; interactions between the environment and the presence or absence of early brain damage; motor neurons and the understanding of others' beliefs and intentions; the effect of physical fitness on cognition and the brain; evidence that our brains work and develop differently from the way traditionally thought; misconceptions that can arise from treating children as if they are simply small adults; and how research with adults can provide insights into developmental processes in children. Each of the 16 articles in the special section forges new territory and crosses disciplinary boundaries. They suggest that investigators look at variables not typically considered, or look at them from perspectives not usually taken, and especially that they pay more attention to interrelations among variables.
\end{abstract}

Keywords: epigenesis, brain development, physical exercise, neuronal synchronous oscillations, Gene $\times$ Environment interactions

This special section of Developmental Psychology is devoted to articles on the interplay of biology and the environment, broadly defined. Each of these papers forges new territory, crosses disciplinary boundaries, or embodies an interdisciplinary approach, and raises points that have the potential to change or challenge how developmental psychologists think. They suggest that investigators look at variables not typically considered, or look at them from perspectives not usually taken, and especially that they pay more attention to interrelations among variables.

Only about $25 \%$ of the submitted articles survived the rigorous review process. We are delighted by their diversity. As can be seen in Table 1, almost half the articles are by scholars outside the United States. About one third of the articles focus largely on neuroimaging or on Gene $\times$ Environment $(\mathrm{G} \times \mathrm{E})$ interactions, although almost all look at behavior and the effects of experience. Most of the contributions focus on aspects of cognition, but a third focus on perception or emotion, and a few on motor functions. Most focus heavily on humans, although a third focus at least as much on animal models, and many of the articles look at both typical development and developmental disorders or psychopathology.

\section{It Is Not Simply That Genes and the Environment Interact}

\section{Experience Affects Gene Expression}

Most of the genes in each person are dormant. Experience affects which genes are turned on (and off), and when. Thus, the environment participates in sculpting expression of the genome.

The writing of this article was supported by Grant R01 DA19685 from the National Institute on Drug Abuse.

Correspondence concerning this article should be addressed to Adele Diamond, Canada Research Chair Professor of Developmental Cognitive Neuroscience, Department of Psychiatry, University of British Columbia, 2255 Wesbrook Mall, Vancouver BC V6T 2A1, Canada. E-mail: adele.diamond@ubc.ca
Meaney and colleagues (Champagne \& Meaney, 2001; Liu, Diorio, Day, Francis, \& Meaney, 2000; Meaney, 2001; Meaney \& Szyf, 2005; Szyf, Weaver, \& Meaney, 2007; Weaver et al., 2004) have demonstrated that the maternal behavior of rats can permanently alter gene expression and influence their offspring's responses to stress throughout life. A long-standing debate in developmental psychology has been whether early experience really produces any long-term, enduring effects. Meaney and colleagues have provided solid evidence that it does, and the effects are not only on psychological variables and behavior but on the genome itself. Early experience can and does have lifelong consequences at all levels, from the molecular to the behavioral.

For example, when rat pups genetically prone to overreact to stress are raised from birth by moms biologically predisposed to be resilient in the face of stress, they take after their moms both in overt behavior and in gene expression. Conversely, when the biological offspring of rats predisposed to be resilient in the face of stress are cross-fostered to moms biologically prone to overreact to stress, they take after their moms throughout life. Further, rats tend to raise their offspring the way they were raised, so these effects are passed down intergenerationally, not through the genes but through behavior (Francis, Diorio, Liu, \& Meaney, 1999). If such epigenetic changes in response to the environment occur in germ cells, they might be transmitted to future generations genetically as well (Anway, Cupp, Uzumcu, \& Skinner, 2005).

Researchers have known for some time that prenatal experience has long-term consequences on physical health, psychological well-being, cognitive functioning, and even gene expression (e.g., Buka, Cannon, Torrey, Yolken, and the Collaborative Study Group on the Perinatal Origins of Severe Psychiatric Disorders, 2008; Cannon et al., 2000; Coe \& Lubach, 2008; Oberlander et al., 2008; Yehuda, Bell, Bierer, \& Schmeidler, 2008; Yehuda \& Bierer, 2008); that early postnatal experience does, as well (e.g., Pollak, 2005); and that, at least in rats, the long-term detrimental conse- 


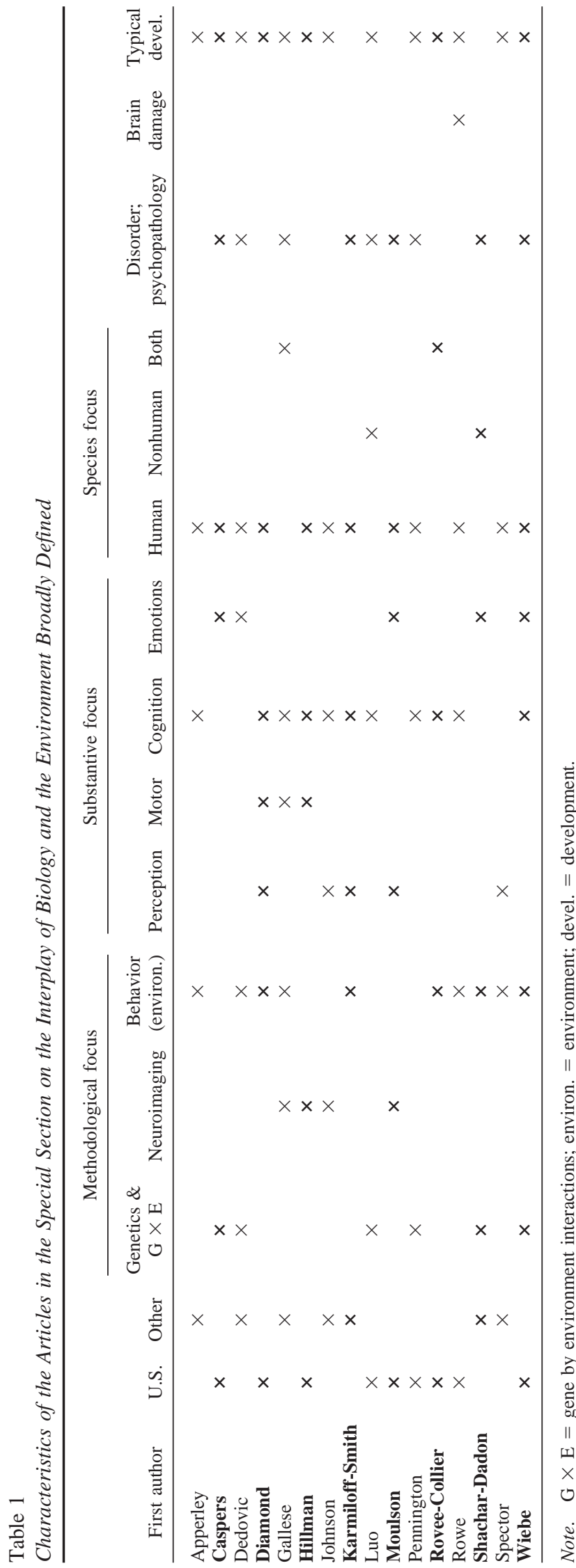

quences of prenatal stress can be prevented by early adoption by a "good mother" (which for rats means that she strokes and licks the pups a lot; Meaney \& Szyf, 2005). A new wrinkle is provided in the article by Shachar-Dadon, Schulkin, and Leshem (2008) in this issue. They provide evidence that stress experienced by the mother well before conception, despite undisturbed pregnancy and postnatal rearing, can have long-lasting effects on her offspring, even into adulthood. Their evidence also suggests that the effects differ by how long before pregnancy the stressful events occurred and by the gender of the offspring.

Epigenetic programming (the turning on and off of genes in response to experience) is stable and long-term, yet reversible and responsive. Recent data suggest that the capacity for epigenetic modification remains active and dynamic throughout life (Meaney \& Szyf, 2005; Szyf, McGowan, \& Meaney, 2008).

\begin{abstract}
An intriguing prospect is that the response of the epigenome to environmental insults throughout life is not just an accidental aberration leading to pathology but a biological mechanism that serves as a medium for the adaptability of the genome to altered environments during life. (Szyf et al., 2008, p. 47)
\end{abstract}

Moulson, Fox, Zeanah, and Nelson (2008) provide evidence of plasticity consistent with that proposition in Romanian children randomly assigned to foster care after horrific early experiences in institutionalized care. Though they did not look at gene expression in this study, they found that foster care at least partially remediated the cortical hypoarousal seen in institutionalized children.

Few studies have investigated whether $\mathrm{G} \times \mathrm{E}$ interactions vary across developmental periods. Wiebe et al. (2008) provide data suggesting they can indeed vary: "The interaction of nature and nurture may differ in its expression in different critical maturation periods" (p. 40). They examined the role of prenatal tobacco exposure, an early experiential factor, and TaqIA genotype, a candidate gene associated with variation in dopamine receptor type 2 (DRD2) expression. They found evidence for $\mathrm{G} \times \mathrm{E}$ interactions in self-regulatory behavior, but the nature of those interactions and the most affected subgroup(s) were different in preschoolers than in infants.

Men and women differ in their responses to different types of stressors and in the prevalence of different stress-related disorders. Part of the reason for that is undoubtedly biological, but Dedovic, Wadiwalla, Engert, and Pruessner (2008) argue in this issue that experience (specifically, gender socialization and social learning) may play a role in shaping these differential responses and differential vulnerabilities to disorders. Certainly that is consistent with recent changes in the relative prevalence of stress-related disorders among men and women, given that there have been no changes in the basic biological differences between the genders.

\section{Genes Affect How the Environment Is Experienced and What Effect a Given Experience Produces}

In this issue, Karmiloff-Smith (2008) elaborates on her neuroconstructivist approach in which genes, brain, cognition, and environment dynamically interact, multidirectionally influencing one another in multiple ways: "Every aspect of development turns out to be dynamic and interactive" (p. 61). It is important to note that a genetic abnormality rarely has an encapsulated effect on only one cognitive function or one brain system because of these extensive, 
ongoing interactions. Karmiloff-Smith argues cogently that it is incorrect to assume that the experienced environment is the same for typically and atypically developing individuals. The biological differences in the latter individuals cause them to experience the world differently, and often cause the world to treat them differently. One cannot assume that the only difference between the two groups is a genetic or neural one. Karmiloff-Smith's neuroconstructivist perspective yields novel, counterintuitive implications for development and for remediation.

In the first study of genetic factors and adult attachment, Caspers et al. (2008) in this issue provide evidence that interindividual variation in the serotonin transporter gene (5-HTTLPR) appears to mediate the effect of the experience of loss of a parent and whether unresolved attachment results from that. The same experience appears to affect different people differently because of their genetic makeup. Parental loss in early childhood is more likely to be unresolved, resulting in unresolved attachment in adulthood, for those who have the short allele polymorphism of the 5-HTTLPR gene. The long allele version of the gene appears to confer some protection in the face of parental loss.

This study, at the interface of molecular genetics and attachment research, is consistent with the role of serotonin in modulating emotional responses (such as fear and anxiety) to environmental stressors and in modulating frontal-amygdala brain circuitry (Firk \& Markus, 2007; Hariri et al., 2002; Heinz et al., 2005). It is also consistent with new results showing an association between the short 5-HTTLPR genotype and disorganized attachment in infants (Spangler, Johann, Ronai, \& Zimmermann, in press) and results showing that the short allele polymorphism of the serotonin transporter gene is associated with deficits in neurobehavioral functioning during infancy if rhesus monkeys are raised by their peers, but not if they are raised by their mothers and peers (Suomi, 2006); those with the long allele version of the gene seem to show normal neurobehavioral functioning regardless of who reared them.

Note, however, that a neurotransmitter does not act in isolation any more than other factors do; the different neurotransmitters interact and affect one another. Dopamine in prefrontal cortex is dramatically elevated in response to even mild stress (Roth, Tam, Ida, Yang, \& Deutch, 1988). Data indicate that inconsistent or disrupted maternal communication tends to produce disorganized attachment only if the child has the short allelic version of a dopamine receptor gene (DRD4; Gervai et al., 2007). Children are more adversely affected by insensitive parenting if they have the 7-repeat allele of the DRD4 gene (Bakermans-Kranenburg \& van Ijzendoorn, 2006). The risk of a child showing externalizing behaviors increases sevenfold if he or she received insensitive care and carries the DRD4 7-repeat allele. Far more work is needed on the interactions between serotonin and dopamine, the interactions between neurotransmitters in general, and their interactions with environmental factors.

The estimated relative contributions of genetic or environmental variations to individual differences in any behavior depend on the range of genetic and environmental differences in the group being studied. Heritability (the proportion of phenotypic variation among individuals attributable to genetic variation) would be zero if everyone were genetically identical, even if genes played a major role in determining outcomes. Similarly, the more homogeneous the environments of those studied are, the higher the heritability estimates will be. If individuals are fortunate enough to live in a favorable environment with few environmental risk factors, genetic risk factors will usually be more decisive in determining who experiences unfavorable outcomes. Also, heritability can be the same in two different environments, although completely different genes might be affecting the outcomes of interest in those two environments.

In this issue, Pennington et al. (2008) ask whether the heritability of the negative (or positive) end of a trait continuum tells us anything about the opposite end of the continuum of that same trait. The answer is pretty much no. Most studies of the heritability of reading or poor attention have looked at the genetic contribution to poor reading or poor attention (e.g., reading disability or attention-deficit/hyperactivity disorder [ADHD]). Reading disability tends to be more heritable in a favorable environment (e.g., Harden, Turkheimer, \& Loehlin, 2007), whereas ADHD tends to be more heritable in a more disadvantaged environment (Laucht et al., 2007; Retz et al., 2008; Seeger, Schloss, Schmidt, RuterJungfleisch, \& Henn, 2004). Besides summarizing that evidence, Pennington et al. look at something largely neglected until now: $\mathrm{G} \times \mathrm{E}$ interactions at the favorable end of the continuum (aboveaverage reading and attention). They find a resilience interaction for above-average reading (the heritability of being a good reader is higher if the parents' level of education is low).

Pennington et al. (2008) also contains an outstanding discussion of many different ways to think about $\mathrm{G} \times \mathrm{E}$ interactions and the many subtleties involved in interpreting them. For instance, what appears to be a $\mathrm{G} \times \mathrm{E}$ interaction might actually be a Gene $\times$ Gene interaction. Also, correlated traits like reading disability and ADHD can enter into opposite $\mathrm{G} \times \mathrm{E}$ interactions, as these authors document. Gene-environment correlations can be positive, creating a positive feedback loop that leads to even more extreme phenotypes over the course of development than either the genetic or environmental factors alone would produce. They can be passive: Parents provide family environments that may be determined in part by their genetic background. Gene-environment correlations can also be evocative: Having a certain genotype may cause individuals to evoke certain responses from others, and in that way the genotype partially shapes the environment. Finally, geneenvironment correlations can be active: Individuals seek out environments friendly to their genetic predispositions; again, one's genetic makeup partially shapes the environment to which one is exposed. These and many more facets of $\mathrm{G} \times \mathrm{E}$ interactions are discussed by Pennington et al. (2008) in their article.

\section{Interactions Between Environmental Input and the Presence or Absence of Early Brain Injury}

Usually, the healthier an organism is, the more environmental degradation the organism can withstand and still prosper. In this issue, Rowe, Levine, Fisher, and Goldin-Meadow (2008) present evidence that for more complex aspects of language (early sentence generation and syntax), but not for simpler aspects (early vocabulary and semantics), caregiver linguistic input is more critical for children with pre- or perinatal left-hemisphere brain damage than for children without brain damage. The same variation in linguistic input led to greater variations in syntactic development among children with brain injury than among those without. Most research on sequelae and plasticity following brain damage has focused on the lesion characteristics; here Rowe et al. (2008) 
provide evidence that environmental factors also affect the extent of recovery. Children with brain damage cannot as easily withstand less-than-optimal environmental input as children with fully intact brains; the range of environmental input that will lead to a good outcome for those with brain damage is narrower, but with excellent environmental input their prognosis can be outstanding.

\section{Dichotomies Such as Mind Versus Body or Action \\ Versus Cognition Are as False as Genes Versus the Environment}

The brain does not recognize the same sharp division between cognitive and motor function that we psychologists impose in our thinking. The same or substantially overlapping brain systems subserve both cognitive and motor functions (Diamond, 2000; Rosenbaum, Carlson, \& Gilmore, 2001). For example, the presupplementary motor area and anterior dorsal premotor cortex are important for sequential tasks, whether they are sequential motor tasks or sequential numerical, verbal, or spatial cognitive tasks (Hanakawa et al., 2002).

\section{Motor Neurons and Understanding the Beliefs and Intentions of Others}

Gallese, Rochat, Cossu, and Sinigaglia (2008) argue cogently that the origin of intentional understanding is anchored in the motor system and that the motor system provides the building blocks upon which more sophisticated social-cognitive abilities are built. Mirror neurons in the brain fire when one executes an action with a certain intent or observes someone else executing the same action with the same intended goal (Rizzolatti, Fadiga, Gallese, \& Fogassi, 1996; Umiltà et al., 2001). Gallese et al. (2008) present evidence that these neurons provide

a parsimonious solution to the problem of translating the results of the visual analysis of an observed movement-in principle, devoid of meaning for the observer-into something that the observer is able to understand to the extent that it refers to his or her own motor knowledge. (p. 104)

Taking advantage of the motor system's functional organization in terms of motor goals and motor intentions, the mirror neuron matching mechanism enables a direct comprehension of the actions of others. Such comprehension is prereflexively accomplished because the behavior of others consists of goal-directed motor acts and is recognized as such by virtue of the activation in the observer's brain of the neurons presiding over the motor accomplishment of that same act. (p. 110)

Although most people contend that only humans have the ability to go below the surface of behavior to infer mental states such as goals and intentions, Gallese et al. (2008) argue that mirror neurons provide a common neural mechanism that permits both humans and nonhuman primates to understand the intentions and beliefs behind actions, their own and others'. According to Gallese et al., nonhuman primates are not simply behavior-readers (as others hold, e.g., Povinelli \& Eddy, 1996; Tomasello \& Call, 1997); instead, like humans, nonhuman primates are mindreaders-not because they think about and ponder the intentions behind actions, but because their mirror neuron system permits direct understanding of the meaning of actions to the extent that the observer is capable of the same or similar behavior.

The relevance of motor disorders in autism has been downplayed for decades, but when cognitive development is perturbed, as in a neurodevelopmental disorder such as autism, motor development is often adversely affected as well. Gallese et al. (2008) argue that a disturbance in motor cognition (as evidenced, for example, in the heavy reliance of children with autism on feedback information for guiding their movements rather than using feedforward modes of motor control as do typically developing children) might be at the basis of some of the social-cognitive impairments in autism:

In contrast to what a long-standing mainstream account of autism contends (see Baron-Cohen, 1995; Baron-Cohen, Leslie, \& Frith, 1985) - that the lack of social understanding of individuals with ASD is due to their inability to theorize about the minds of others-we contend that theorizing is most likely the only compensatory strategy available to them. Many of the social-cognitive impairments manifested by individuals with ASD are rooted in their incapacity to organize and directly grasp the intrinsic goal-related organization of motor behavior. (p. 110)

\section{Effects of Physical Fitness and Physical Health on Cognition and the Brain}

People aren't simply thinking, feeling, and sensing machines; we also have bodies. Our brains work better when our bodies are physically fit. There are multiple reciprocal interrelations between our nervous, immune, and endocrine systems (e.g., Cohen, Alper, Doyle, Treanor, \& Turner, 2006; Cohen \& Pressman, 2006; Maier, Watkins, \& Fleshner, 1994; Robles, Glaser, \& Kiecolt-Glaser, 2005). If we are not in good physical health, we do not think as well.

Much research has shown that exercising and being physically fit can help protect older adults against age-related cognitive decline (Kramer \& Hillman, 2006). The positive effects of aerobic physical activity on cognition and brain function for older adults have been demonstrated at the molecular, cellular, systems, and behavioral levels (Hillman, Erickson, \& Kramer, 2008). In this issue, Hillman, Buck, Themanson, Pontifex, \& Castelli (2008) extend that work by showing benefits to executive function and cognitive control from aerobic exercise in young children and by providing an initial understanding of the mechanisms that may underlie the effects of physical fitness on cognitive functions during development. Leading a sedentary life appears to be as bad for children's cognitive health as it is for adults. At a time when schools are pressured to devote more time and resources to academics and less to physical education, Hillman, Buck, et al. (2008) indicate that programs that promote physical fitness not only improve physical health, but cognitive health and academic achievement as well.

\section{Our Brains May Not Work, or Develop, the Way We Have Traditionally Thought}

Most people tend to think of gross commands as only characterizing the immature brain, but they are very much true of the mature adult brain as well. In this issue (Diamond, 2008), I offer the hypothesis that the mind and brain often tend to work at a 
relatively gross level and only with effort (often in the form of inhibition) work more selectively, even in adults. Most of us tend to think of the nervous system as sending out very precise commands only to the relevant recipient, but it appears that often the command goes out more globally, and then parts of the system need to be inhibited from acting on the command. The lack of specification that surprised neuroscientists when they first discovered exuberant projections decades ago seems to be the rule across many domains of cognition, perception, and action, even when one might think the domains being issued the same global command should be distinct. Executing more differentiated commands appears to require inhibition of what I call the global-command default. This simple principle applies to disparate work within cognitive science and neuroscience. For example, it is easier to switch everything or nothing than to switch one thing (e.g., the rule one is following or which button to press) but not the other, throughout development. Although response site (e.g., press right or left) and rule (e.g., "Always press on the side opposite the stimulus," or "Always press on the same side as the stimulus") should be orthogonal, evidently both seem to be affected by a global command to "change" or "repeat" (Davidson, Amso, Anderson, \& Diamond, 2006). When people want to do something with the right hand, both the right and the left hands receive the command to do it, and the movement of the left hand has to be actively inhibited (Sohn, Jung, Kaelin-Lang, \& Hallett, 2003).

The brain is more than neurons and neurotransmitters. Glia, hormones, regulatory peptides, and more play critical roles as well. Integrating findings from the fields of biochemistry, pharmacology, genetics, and nutrition, Luo, Wagner, and Dräger (2008) offer novel ideas and hypotheses in this issue about the role of retinoic acid in brain development, plasticity, and function. Retinoic acid (a lipid derived from vitamin A) regulates the transcription of about one sixth of the human genome (Cawley et al., 2004). One of retinoic acid's important properties is that it can diffuse for longer distances through tissue than any known peptide signaling factor (Lander, 2007), potentially a powerful tool for connecting spatially disparate neuronal assemblies in the brain. Luo et al. (2008) propose that retinoic acid contributes topographical information in the brain and contributes to designating areas of relatively modifiable or relatively fixed neuronal circuitry.

Although functional neuroimaging enables researchers to see patterns of activity simultaneously in multiple brain regions, we are still too prone to think in terms of one-to-one mappings between neural regions and cognitive abilities. We still tend to think of the neural changes that accompany or make possible cognitive advances as being in individual neural regions. In this issue, Johnson, Grossmann, and Kadosh (2008) argue for taking seriously the role of interactions between brain regions in neural and cognitive development. According to their interactive specialization view,

the response properties of a specific region are partly determined by its patterns of connectivity to other regions and, in turn, by their patterns of activity. During postnatal development, changes in the response properties of cortical regions occur as they interact and compete with each other. (p. 151)

Johnson et al. (2008) also argue that prefrontal cortex may play a role in orchestrating the collective functional organization of other cortical regions during development, and that networks that in- clude prefrontal cortex may be able to learn certain tasks faster or learn tasks that other networks cannot because prefrontal cortex

can recruit the knowledge and computational ability of other selfcontained networks as and when required. In a sense, it selects from a library of available computational systems to orchestrate the best combination for the learning problem at hand. (p. 157)

This orchestration is done partly through synchronous oscillations. One of the ways in which brain regions communicate with each other is in the temporal domain, relying on coincidence of neuronal activity. Neurons oscillate their firing at different frequencies (e.g., alpha, beta, delta, gamma, and theta). Neurons participating in the same oscillatory rhythm synchronize their discharges with very high precision. Synchronization is used to increase the salience of signals, facilitate their propagation across sparsely connected networks, and assure selective routing (Ford, Krystal, \& Mathalon, 2007; Uhlhaas, Haenschel, Nikolić, \& Singer, 2008). The synchrony of neuronal activity is more closely related to behavior than is its amplitude (Pinto, Brumberg, \& Simons, 2000).

The specific frequency of synchronous firing appears to identify neuron groupings as belonging to the same functional network, allowing the same neurons to participate in different processes with other neurons. Hence, synchronous oscillations in a wide range of frequencies play a role in linking spatially distributed neuronal assemblies into functionally integrated and specialized networks (Ford et al., 2007; Singer, 1999; Fries, 2005; Gray, 1999).

The same group of neurons can produce more than one frequency (Blatow et al., 2003; Hughes et al., 2004; Lisman \& Buzsáki, 2008):

A characteristic of oscillations in cortical networks is that multiple frequency bands coexist, and there is evidence that interactions between oscillations at different frequencies are used for the encoding of nested relations (for a review, see Jensen and Colgin, 2007). (Uhlhaas et al., 2008, p. 932)

Cells that are more strongly excited tend to fire earlier (Konig, Engel, Roelfsema, \& Singer, 1995). This provides an efficient mechanism for encoding information redundant or complementary to that provided by the rate of firing. This additional information allows for more precision. An important advantage of this should be increases in the speed with which a neural system can conduct computations (Uhlhaas et al., 2008). Although much of the focus on explaining improvements in processing speed with age has been on myelination, it may be that participation of the prefrontal cortex in a network improves processing speed because it may be able to synchronize widely distributed neuronal activity.

\section{Infants and Children Are Not Simply Miniature Adults}

Most people would agree that implicit (nondeclarative) memory matures early and is present in infants, whereas explicit (declarative) memory matures later (Richmond \& Nelson, 2007). In a provocative article in this issue, Rovee-Collier and Cuevas (2008) argue that this is the wrong way to think about infant memory. They argue that "because adults and infants occupy different niches, what they perceive, learn, and remember about the same event differs, but their raw capacity to learn and remember does 
not" (p. 160). They view children and adults as "different organisms who occupy different ecological niches that pose different sets of problems to solve" (p. 168). As a result of being faced with different problems, infants and adults learn and remember different things about the same event. Infants can rapidly learn some associations that adults cannot learn at all or learn only with difficulty and can perceive certain aspects of events that adults cannot. Rovee-Collier and Cuevas (2008) argue that

the underlying process does not change ontogenetically, but the content of what is learned and remembered does. Instead of asking whether infants remember over the long term, research in this tradition focuses on what they remember and under what conditions they remember it. (p. 170)

\section{On the Other Hand, Research With Adults Can Provide Insights Into Developmental Processes in Children}

Spector and Maurer (2008) lay out a carefully reasoned argument that synesthesia (where a stimulus induces not only the usual perception but also a seemingly automatic additional perception, such as always seeing a certain color when one sees or hears a certain letter or number; Cytowic, 2002, 2003) in adults is "far more than a quirky phenomenon: It is a window into the very nature of sensory processing and development" (p. 185), which in turn influences the development of perception and language and may constrain the learning of environmentally based associations. Spector and Maurer argue that synesthesia is based on the magnification of functional connections within and between sensory areas present early in life that are normally pruned or inhibited during development but persist in muted forms in all adults. They use this perspective to generate novel, testable hypotheses about intersensory development. For example, they predict that toddlers go through a developmental phase in which they experience synesthetic perceptions. This article challenges the way synesthesia and intersensory development have been conceptualized and studied thus far.

Bridging work in developmental psychology, neuropsychological studies in adults, and social psychology, Apperly, Samson, and Humphreys (2008) show how studies in adults can inform the understanding of theory of mind development. Studies in children have seemed to indicate that the development of theory-of-mind reasoning is dependent upon the development of both executive functions and language (theory of mind and executive functions, e.g., Perner \& Lang, 1999; theory of mind and language, e.g., Astington \& Baird, 2005). Apperly et al. (2008) show that recent work in adults indicates that impaired executive functioning impairs theory-of-mind reasoning, but that even severely impaired grammar can leave theory-of-mind reasoning intact. These findings in adults suggest that the interpretation of the relation between theory of mind and developmental advances in grammar, on the one hand, should perhaps be interpreted differently from observed relations between theory-of-mind development and developmental advances in executive functions, on the other hand.

We hope the articles in this special section are thought provoking and encourage ever more dialogue and collaboration among people in different subspecialties within developmental psychology and between those in developmental psychology and those in other disciplines.

\section{References}

Anway, M. D., Cupp, A. S., Uzumcu, M., \& Skinner, M. K. (2005, June 3). Epigenetic transgenerational actions of endocrine disruptors and male fertility. Science, 308, 1466-1469.

Apperley, I. A., Samson, D., \& Humphreys, G. W. (2008). Studies of adults can inform accounts of theory of mind development. Developmental Psychology, 45, 190-201.

Astington, J. W., \& Baird, J. A. (Eds.). (2005). Why language matters for theory of mind. Oxford, England: Oxford University Press.

Bakermans-Kranenburg, M. J., \& van Ijzendoorn, M. H. (2006). Geneenvironment interaction of the dopamine D4 receptor (DRD4) and observed maternal insensitivity predicting externalizing behavior in preschoolers. Developmental Psychobiology, 48, 406-409.

Baron-Cohen, S. (1995). Mindblindness. Cambridge, MA: MIT Press.

Baron-Cohen, S., Leslie, A. M., \& Frith, U. (1985). Does the autistic child have a "theory of mind"? Cognition, 21, 37-46.

Blatow, M., Rozov, A., Katona, I., Hormuzdi, S. G., Meyer, A. H., Whittington, M. A., et al. (2003). A novel network of multipolar bursting interneurons generates theta frequency oscillations in neocortex. Neuron, 38, 805-817.

Buka, S. L., Cannon, T. D., Torrey, E. F., Yolken, R. H., \& Collaborative Study Group on the Perinatal Origins of Severe Psychiatric Disorders. (2008). Maternal exposure to herpes simplex virus and risk of psychosis among adult offspring. Biological Psychiatry, 63, 809-815.

Cannon, T. D., Rosso, I. M., Hollister, J. M., Bearden, C. E., Sanchez, L. E., \& Hadley, T. (2000). A prospective cohort study of genetic and perinatal influences in the etiology of schizophrenia. Schizophrenia Bulletin, 26, 351-366.

Caspers, K., Paradiso, S., Yuvuis, R., Troutman, B., Arndt, S., \& Philibert, R. (2008). Association between the serotonin transporter promoter polymorphism (5-HTTLPR) and adult unresolved attachment. Developmental Psychology, 45, 64-76.

Cawley, S., Bekiranov, S., Ng, H. H., Kapranov, P., Sekinger, E. A., Kampa, D., et al. (2004). Unbiased mapping of transcription factor binding sites along human chromosomes 21 and 22 points to widespread regulation of noncoding RNAs. Cell, 116, 499-509.

Champagne, F. A., \& Meaney, M. J. (2001). Like mother, like daughter: Evidence for non-genomic transmission of parental behavior and stress responsivity. Progress in Brain Research, 133, 287-302.

Coe, C. L., \& Lubach, G. R. (2008). Fetal programming: Prenatal origins of health and illness. Current Directions in Psychological Science, 17, $36-41$.

Cohen, S., Alper, C., Doyle, W., Treanor, J. \& Turner, R. (2006). Positive emotional style predicts resistance to illness after experimental exposure to rhinovirus or influenza a virus. Psychosomatic Medicine, 68, 809815.

Cohen, S., \& Pressman, S. (2006). Positive affect and health. Current Directions in Psychology, 15, 122-125.

Cytowic, R. E. (2002). Synesthesia: A union of the senses (2nd ed.). Cambridge, MA: Bradford Books.

Cytowic, R. E. (2003). The man who tasted shapes. Cambridge, MA: MIT Press.

Davidson, M. C., Amso, D., Anderson, L. C., \& Diamond, A. (2006). Development of cognitive control and executive functions from 4-13 years: Evidence from manipulations of memory, inhibition, and task switching. Neuropsychologia, 44, 2037-2078.

Dedovic, K., Wadiwalla, M., Engert, V., \& Pruessner, J. C. (2008). The role of sex and gender socialization in stress reactivity. Developmental Psychology, 45, 45-55.

Diamond, A. (2000). Close interrelation of motor development and cognitive development and of the cerebellum and prefrontal cortex. Child Development, 71, 44-56.

Diamond, A. (2008). All or none hypothesis: A global-default mode that 
characterizes the brain and mind. Developmental Psychology, 45, 130138.

Firk, C., \& Markus, C. R. (2007). Serotonin by stress interaction: A susceptibility factor for the development of depression? Journal of Psychopharmacology, 21, 538-544.

Ford, J. M., Krystal, J. H., \& Mathalon, D. H. (2007). Neural synchrony in schizophrenia: From networks to new treatments. Schizophrenia Bulletin, 33, 848-852.

Francis, D., Diorio, J., Liu, D., \& Meaney, M. J. (1999, November 5). Nongenomic transmission across generations of maternal behavior and stress responses in the rat. Science, 286, 1155-1158.

Fries, P. (2005). A mechanism for cognitive dynamics: Neuronal communication through neuronal coherence. Trends in Cognitive Science, 9, 474-480.

Gallese, V., Rochat, M., Cossu, G., \& Sinigaglia, C. (2008). Motor cognition and its role in the phylogeny and ontogeny of action understanding. Developmental Psychology, 45, 103-113.

Gervai, J., Novak, A., Lakatos, K., Toth, I., Danis, I., Ronai, Z., et al. (2007). Infant genotype may moderate sensitivity to maternal affective communications: Attachment disorganization, quality of care, and the DRD4 polymorphism. Social Neuroscience, 2, 307-319.

Gray, C. M. (1999) The temporal correlation hypothesis of visual feature integration: Still alive and well. Neuron, 24, 31-47.

Hanakawa, T., Honda, M., Sawamoto, N., Okada, T., Yonekura, Y., Fukuyama, H., \& Shibasaki, H. (2002). The role of rostral Brodmann area 6 in mental-operation tasks: An integrative neuroimaging approach. Cerebral Cortex, 12, 1157-1170.

Harden, K. P., Turkheimer, E., \& Loehlin, J. C. (2007). Genotype by environment interaction in adolescents' cognitive aptitude. Behavior Genetics, 37, 273-283.

Hariri, A. R., Mattay, V. S., Tessitore, A., Kolachana, B., Fera, F., Goldman, D., et al. (2002, July 19). Serotonin transporter genetic variation and the response of the human amygdala. Science, 297, 400-403.

Heinz, A., Braus, D. F., Smolka, M. N., Wrase, J., Puls, I., Hermann, D., et al. (2005). Amygdala-prefrontal coupling depends on a genetic variation of the serotonin transporter. Nature Neuroscience, 8, 20-21.

Hillman, C. H., Buck, S. M., Themanson, J. R., Pontifex, M. B., \& Castelli, D. M. (2008). Aerobic fitness and cognitive development: Event-related brain potential and task performance indices of executive control in preadolescent children. Developmental Psychology, 45, 114-129.

Hillman, C. H., Erickson, K. I., \& Kramer, A. F. (2008). Be smart, exercise your heart: Exercise effects on brain and cognition. Nature Reviews Neuroscience, 9, 58-65.

Hughes, S. W., Lörincz, M., Cope, D. W., Blethyn, K. L., Kékesi, K. A., Parri, H. R., et al. (2004). Synchronized oscillations at alpha and theta frequencies in the lateral geniculate nucleus. Neuron, 42, 253-268.

Jensen, O., \& Colgin, L. L. (2007). Cross-frequency coupling between neuronal oscillations. Trends in Cognitive Science, 11, 267-269.

Johnson, M. H., Grossmann, T., \& Kadosh, K. C. (2008). Mapping functional brain development: Building a social brain through interactive specialization. Developmental Psychology, 45, 151-159.

Karmiloff-Smith, A. (2008). Nativism versus neuroconstructivism: Rethinking the study of developmental disorders. Developmental Psychology, 45, 56-63.

Konig, P., Engel, A. K., Roelfsema, P. R., \& Singer, W. (1995). How precise is neuronal synchronization? Neural Computation, 7, 469-485.

Kramer, A. F., \& Hillman, C. H. (2006). Aging, physical activity, and neurocognitive function. In E. Acevado \& P. Ekkekakis (Eds.), Psychobiology of physical activity (pp. 45-59). Champaign, IL: Human Kinetics.

Lander, A. D. (2007). Morpheus unbound: Reimagining the morphogen gradient. Cell, 128, 245-256.

Laucht, M., Skowronek, M. H., Becker, K., Schmidt, M. H., Esser, G., Schulze, T. G., et al. (2007). Interacting effects of the dopamine trans- porter gene and psychosocial adversity on attention-deficit/hyperactivity disorder symptoms among 15-year-olds from a high-risk community sample. Archives of General Psychiatry, 64, 585-590.

Lisman, J., \& Buzsáki, G. (2008). A neural coding scheme formed by the combined function of gamma and theta oscillations. Schizophrenia Bulletin, 34, 974-980.

Liu, D., Diorio, J., Day, J. C., Francis, D. D., \& Meaney, M. J. (2000). Maternal care, hippocampal synaptogenesis and cognitive development in rats. Nature Neuroscience, 3, 799-806.

Luo, T., Wagner, E., \& Dräger, U. C. (2008). Integrating retinoic acid signaling with brain function. Developmental Psychology, 45, 139-150.

Maier, S. F., Watkins, L. R., \& Fleshner, M. (1994). Psychoneuroimmunology: The interface between behavior, brain, and immunity. American Psychologist, 49, 1004-1017.

Meaney, M. J. (2001). Maternal care, gene expression, and the transmission of individual differences in stress reactivity across generations. Annual Review of Neuroscience, 24, 1161-1192.

Meaney, M. J., \& Szyf, M. (2005). Maternal care as a model for experience-dependent chromatin plasticity? Trends in Neurosciences, 28, 456-463.

Moulson, M. C., Fox, N. A., Zeanah, C. H., \& Nelson, C. A. (2008). Early adverse experiences and the neurobiology of facial emotion processing. Developmental Psychology, 45, 17-30.

Oberlander, T., Weinberg, J., Papsdorf, M., Grunau, R., Misri, S., \& Devlin, A. (2008). Prenatal exposure to maternal depression, neonatal methylation of human glucocorticoid receptor gene (NR3C1) and infant cortisol stress responses. Epigenetics, 3, 1-9.

Pennington, B. F., McGrath, L. M., Rosenberg, J., Barnard, H., Smith, S. D., Willcutt, E. G., et al. (2008). Gene $\times$ Environment interactions in reading disability and attention-deficit/hyperactivity disorder. Developmental Psychology, 45, 77-89.

Perner, J., \& Lang, B. (1999). Development of theory of mind and executive control. Trends in Cognitive Sciences, 3, 337-344.

Pinto, D. J., Brumberg, J. C., \& Simons, D. J. (2000). Circuit dynamics and coding strategies in rodent somatosensory cortex. Journal of Neurophysiology, 83, 1158-1166.

Pollak, S. D. (2005). Early adversity and mechanisms of plasticity: Integrating affective neuroscience with developmental approaches to psychopathology. Development and Psychopathology, 17, 735-752.

Povinelli, D. J., \& Eddy, T. J. (1996). What young chimpanzees know about seeing. Monographs of the Society for Research in Child Development, 61, 1-152.

Retz, W., Freitag, C. M., Retz-Junginger, P., Wenzler, D., Schneider, M., Kissling, C., et al. (2008). A functional serotonin transporter promoter gene polymorphism increases ADHD symptoms in delinquents: Interaction with adverse childhood environment. Psychiatry Research, 158, 123-131.

Richmond, J., \& Nelson, C. A. (2007). Accounting for change in declarative memory: A cognitive neuroscience perspective. Developmental Review, 27, 349-373.

Rizzolatti, G., Fadiga, L., Gallese, V., \& Fogassi, L. (1996). Premotor cortex and the recognition of motor actions. Cognitive Brain Research, 3, 131-141.

Robles, T. F., Glaser, R., \& Kiecolt-Glaser, J. K. (2005). Out of balance: A new look at chronic stress, depression, and immunity. Current Directions in Psychological Science, 14, 111-115.

Rosenbaum, D. A., Carlson, R. A., \& Gilmore, R. O. (2001). Acquisition of intellectual and perceptual-motor skills. Annual Review of Psychology, 52, 453-470.

Roth, R. H., Tam, S. Y., Ida, Y., Yang, J. X., \& Deutch, A. Y. (1988). Stress and the mesocorticolimbic dopamine systems. Annals of the New York Academy of Sciences, 537, 138-147.

Rovee-Collier, C., \& Cuevas, K. (2008). Multiple memory systems are 
unnecessary to account for infant memory development: An ecological model. Developmental Psychology, 45, 160-174.

Rowe, M. L., Levine, S. C., Fisher, J. A., \& Goldin-Meadow, S. (2008). Does linguistic input play the same role in language learning for children with and without early brain injury? Developmental Psychology, 45, $64-76$.

Seeger, G., Schloss, P., Schmidt, M. H., Ruter-Jungfleisch, A., \& Henn, F. A. (2004). Gene-environment interaction in hyperkinetic conduct disorder $(\mathrm{HD}+\mathrm{CD})$ as indicated by season of birth variations in dopamine receptor (DRD4) gene polymorphism. Neuroscience Letters, 366, 282-286.

Shachar-Dadon, A., Schulkin, J., \& Leshem, M. (2008). Adversity before conception will affect adult progeny in rats. Developmental Psychology, $45,9-16$.

Singer, W. (1999). Neuronal synchrony: A versatile code for the definition of relations? Neuron, 24, 49-65, 111-125.

Sohn, Y. H., Jung, H. Y., Kaelin-Lang, A. \& Hallett, M. (2003). Excitability of the ipsilateral motor cortex during phasic voluntary hand movement. Experimental Brain Research, 148, 176-185.

Spangler, G., Johann, M., Ronai, Z., \& Zimmermann, P. (in press). Genetic and environmental influence on attachment disorganization. Journal of Child Psychology and Psychiatry.

Spector, F., \& Maurer, D. (2008). Synesthesia: A new approach to understanding the development of perception. Developmental Psychology, 45, 175-189.

Suomi, S. J. (2006). Risk, resilience, and Gene $\times$ Environment interactions in rhesus monkeys. Annals of the New York Academy of Sciences, 1094, 83-104.

Szyf, M., McGowan, P., \& Meaney, M. J. (2008). The social environment and the epigenome. Environmental and Molecular Mutagenesis, 49, 46-60.

Szyf, M., Weaver, I., \& Meaney, M. J. (2007). Maternal care, the epigenome and phenotypic differences in behavior. Reproductive Toxicology, 24, 9-19.

Tomasello, M., \& Call, J. (1997). Primate cognition. New York: Oxford University Press.

Uhlhaas, P. J., Haenschel, C., Nikolić, D., \& Singer, W. (2008). The role of oscillations and synchrony in cortical networks and their putative relevance for the pathophysiology of schizophrenia. Schizophrenia Bulletin, 34, 927-943.

Umiltà, M. A., Kohler, E., Gallese, V., Fogassi, L., Fadiga, L., Keysers, C., \& Rizzolatti, G. (2001). "I know what you are doing": A neurophysiological study. Neuron, 32, 91-101.

Weaver, I. C. G., Cervoni, N., Champagne, F. A., D'Alessio, A. C., Sharma, S., Seckl, J. R., et al. (2004). Epigenetic programming by maternal behavior. Nature Neuroscience, 7, 847-854.

Wiebe, S. A., Espy, K. A., Stopp, C., Respass, J., Stewart, P., Jameson, T. R., et al. (2008). Gene-environment interactions across development: Exploring DRD2 genotype and prenatal smoking effects on selfregulation. Developmental Psychology, 45, 31-44.

Yehuda, R., Bell, A., Bierer, L. M., \& Schmeidler, J. (2008). Maternal, not paternal, PTSD is related to increased risk for PTSD in offspring of Holocaust survivors. Journal of Psychiatric Research, 42, 1104-1111.

Yehuda, R, \& Bierer, L. M. (2008). Transgenerational transmission of cortisol and PTSD risk. Progress in Brain Research, 167, 121-135.

Received November 6, 2008 Accepted November 7, 2008 